gewann Interesse an der Außenwelt, hatte den Mut, allein spazieren zu gehen, und zeigte eine gewisse Lebensfreude.

Daß die Röntgenstrahlen die Reflexe herabsetzen, ist eine bekannte Tatsache. Auch ist die Herabsetzung der Reflexerregbarkeit durch Bestrahlung des Großhirns im Tierexperiment durch Tarchan off nachgewiesen; hierauf beruht ja wohl auch die analgetische Wirkung der Röntgenstrahlen und ihr Einfluß auf die verschiedensten Schmerzzustände, wie sie Zimmern, F. Cottenot, Pariaux, Straßburger, Simonson, Eckstein, Sänger u. v. a. klinisch beobachtet und beschrieben haben. Es wäre sicherlich eine Ueberwertung der Wirksamkeit der Strahlentherapie, wenn man annehmen wollte, daß eine so schwere Form von Jacksonscher Epilepsie, wie der eben besprochene Fall M., allein durch die Bestrahlung zur bedeutenden Besserung gebracht worden sei. Ich habe die feste Ueberzeugung, da $\beta$ hier doch in erster Linie die Entfernung des Krampfzentrums für den Erfolg als ursächliches Moment in Betracht kommt. Jedoch war die Wirkung der Operation unvollkommen, konnte aber durch die Bestrahlung komplettiert werden. Da wir heute in einer Zeit leben, in welcher infolge der zahlreichen Schädelschußverletzungen die Bedeutung solcher sčhweren $\mathrm{Zu}-$ stände eine ganz andere ist als früher, so möchte ich doch jetzt schon die Aufmerksamkeit auf die Wirkung der Strahlenbehandlung bei epileptischen Zuständen - auch ganz besonders auf ihre Verwendbarkeit zur chirurgischen Nachbehandlung - lenken, ohne mir darüber, im unklaren zu sein, da $\beta$ mein bisheriges Beobachtungsmaterial noch viel zu klein ist, um schon allgemeine Grundsätze davon ableiten zu können.

Aus der Röntgenabteilung der Kaiser-Wilhelms-Akademie in Berlin. \section{Ueber Wirkung der Strahlenbehandlung bei Epilepsie.}

Von Stabsarzt Otto Strauss, Vorstand der Abteilung.

Ich habe schon 1913 einnthal ${ }^{1}$ ) in Kürze darauf aufmerksam gemacht, da $\beta$ es mir gelungen ist, mit Hilfe von Bestrahlungen bei epileptischen Zuständen eine Besserung $\mathrm{zu}$ erzielen. Ich lie $\boldsymbol{B}$ es in dieser ersten Mitteilung durchaus dahingestellt, ob es sich um eine reine Strahlenwirkung handelte, und ich sprach die Vermutung aus, daß eine Suggestivwirkung hier mit im Spiele sei. Diese Mitteilung griff H. Eckstein²) sowohl auf dem Röntgenkongreß 1914 wie in einer Beschreibung bisher unbekannter Wirkungen der Röntgenstrahlen und ihrer therapeutischen Verwertung auf, weitere Nachprüfungen haben, soweit ich die Röntgenliteratur während des Krieges zu verfolgen in der Lage war, nicht stattgefunden. Aus dem Feldzuge zurückgekehrt, wandte ich mich sofort wieder dieser Bestrahlungsform $\mathrm{zu}$ und bin heute in der Lage, eine sehr bemerkenswerte Mitteilung zu machen:

Die 22 jährige, unverheiratete M. M. leidet nach Angabe der Eltern seit dem dritten Lebensjahre an schweren epileptischen Zuständen. Diese nahmen im Laufe der Jahre zu, befielen die rechte Körperseite und beide Gesichtshälften. Die Anfälle wurden zuletzt so häufig, daß nur noch ganz kurze Zwischenpausen die einzelnen Anfälle trennten. Angeblich kam es zeitweise alle fünf Minuten zu schwersten Anfällen, die mit Bewußtseinsverlust und klonischen Zuckungen (vorwiegend des rechten Armes) einhergingen. Es bestand Unfähigkeit zu gehen, die anscheinend aber auf die Angst vor dem Hinstürzen bei plötzlich auftretenden Anfällen zurückzuführen ist. Da der Zustand absolut trostlos war, entschloß man sich im elften Lebensjahre der Patientin zu einer operativen Behandlung. Es wurde das Krampfzentrum für den rechten Arm exzidiert. Die Operation hatte insofern auch einen Erfolg, als die Anfälle nicht mehr in dieser Kraft und Stärke, wohl auch nicht mehr mit derselben Häufigkeit auftraten. Es konnten später auch Gehversuche angestellt werden. Der rechte Arm blieb nach der Operation gelähmt. Indessen traten immer noch sehr zahlreiche Anfälle auf, die nunmehr mit Luminal und großen Dosen von Bromkalium bekämpft wurden. Angeblich hatte diese Arzneibehandlung seit Vornahme der Operation auch einigen Erfolg, jedoch konnte der Gesamtzustand nicht als günstig bezeichnet werden, indem eben noch täglich Anfälle auftraten. Ich verabreichte der $\mathrm{Pa}-$ tientin vier Erythemdosen harter gefilterter Strahlen in vier Sitzungen mit je vier Wochen Zwischenpause. Bestrahlt wurde die linke Zentralfurche, zum Schutze des Kopfhaars wurde der nicht in Betracht kommende Teil des Schädels stark abgedeckt.

Der Erfolg der Behandlung war außerordentlich. Die schweren Anfälle mit Bewußtseinsverlust schwanden, es blieben nur noch ab und zu auftretende, leichte klonische Zuckungen übrig, die aber auch nur selten waren. Luminal und Brom konnten ausgesetzt werden. Das junge Mädchen blühte sichtlich auf,

2) M. Kl. $1913 \mathrm{Nr} 34 .{ }^{2}$ ) B. kl. W. $1914 \mathrm{Nr} .36$. 